\title{
A família da criança com doença falciforme e a equipe enfermagem: revisão crítica
}

\author{
The family of the child with sickle cell disease and the nursing team: critical review
}

Carmen C. M. Rodrigues ${ }^{1}$

Izilda E. M. Araújo ${ }^{2}$

Luciana L. Melo ${ }^{2}$

\begin{abstract}
Trata-se de uma revisão crítica da literatura com vistas a evidenciar o estado da arte da temática família da criança com doença falciforme e a relação com a equipe de enfermagem. Foram utilizadas as bases de dados PubMed, Lilacs, SciELO, BDENF e Medline, com os descritores anemia falciforme, enfermagem, família e criança. Foram selecionados 11 artigos e realizada análise quantitativa e qualitativa, sendo esta fundamentada no referencial de análise de conteúdo, emergindo os seguintes temas: conhecimento científico, assistência de enfermagem e educação. Evidenciouse a necessidade do conhecimento cientifico sobre doença falciforme para que a assistência de enfermagem seja efetiva e contribua com uma melhor qualidade de vida e aumento da sobrevida destas crianças. Vale ressaltar que a produção brasileira sobre doença falciforme e seus envolvidos - família, criança e equipe de enfermagem-é escassa e incipiente. Rev. Bras. Hematol. Hemoter. 2010;32(3):257-264.
\end{abstract}

Key words: Anemia falciforme; criança; família; cuidados de enfermagem.

\section{Introdução}

A doença falciforme foi descrita por Herrick, em 1910, em um estudante da Universidade das Índias Ocidentais, proveniente de Granada, na América Central, no qual se observou, à microscopia, o aspecto anômalo e alongado das hemácias. ${ }^{1}$

A doença falciforme é a doença hereditária monogênica mais comum do Brasil, ocorrendo predominantemente entre afrodescendentes, decorrente de uma única alteração na molécula de hemoglobina $(\mathrm{Hb})$, onde a $\mathrm{Hb}$ anormal S é produzida no lugar da $\mathrm{Hb}$ normal $\mathrm{A} .{ }^{2}$

Embora tratável, a doença falciforme ainda é incurável. O tratamento precoce comprovadamente aumenta a sobrevivência das crianças afetadas e melhora a qualidade de vida, mas não possibilita a cura clínica. Estas crianças deverão ser acompanhadas ao longo da vida em um centro de tratamento que ofereça uma abordagem abrangente por meio de uma equipe multiprofissional especializada, com avaliações clínicas periódicas e internações hospitalares em situações de risco. Sem o acompanhamento clínico especializado, os benefícios obtidos pelo tratamento precoce não serão consolidados..$^{2-3}$

Reconhecendo a importância epidemiológica da doença falciforme, dois importantes passos foram dados pelo Governo Federal: a elaboração do "Programa Anemia Falciforme (PAF)", em 1996, e a criação do "Programa Nacional de Triagem Neonatal (PNTN)", em 2001, Portaria GM/MS n 822/01, que estabeleceu a inclusão de testes para identificação da doença falciforme nos exames de rotina realizados em todos os recém-nascidos brasileiros, conhecido como "teste do pezinho". ${ }^{2}$

A triagem neonatal pode salvar vidas, mas a forma como os pais compreendem este resultado é também importante para a adesão aos planos de tratamento e para evitar complicações psicossociais. ${ }^{4}$ Deste modo, o avanço no trata-

${ }^{I}$ Enfermeira coordenadora dos programas abrangentes da Hematologia. Centro Infantil Boldrini - Campinas - SP.

${ }^{2}$ Enfermeira. Professora do Departamento de Enfermagem, Faculdade de Ciências Médicas - Unicamp - Campinas-SP.

Centro Infantil Boldrini, Universidade Estadual de Campinas (Unicamp) - Campinas-SP.

Correspondência: Carmen Cunha Mello Rodrigues

Rua Pernambuco, 86 - São Bernardo

13031-300 - Campinas-SP - Brasil

E-mail:carmencmr@bol.com.br

Doi: $10.1590 /$ S1516-84842010005000079 
mento da doença e a consequente melhora da sobrevida dos pacientes estão intrinsecamente ligados à forma como a família é acolhida e orientada a partir do diagnóstico. Esta orientação geralmente é realizada pela enfermeira, além do hematologista.

Por se tratar de uma doença crônica, o tratamento será ao longo da vida e, para que este seja bem sucedido, os familiares da criança recém-diagnosticada necessitarão aprender sobre os sinais de complicações, bem como a agir corretamente nas diferentes intercorrências. ${ }^{5-6}$ Os pais aprenderão a prevenir e reconhecer as crises de dor, manejar analgésicos e outras medidas para alívio da mesma, reconhecer precocemente sinais de infecção e de infarto cerebral, palpar o baço e identificar a crise de sequestro esplênico, entre outras informações vitais para a sobrevivência da criança.

Para a enfermeira atuar junto à família da criança no aprendizado com relação à doença, é necessário que ela compreenda quais são os recursos importantes para a família no enfrentamento de situações estressantes que envolvem, necessariamente, o conviver com a doença. Durante a hospitalização e/ou atendimento ambulatorial da criança, a enfermeira tem diversas oportunidades de estar com seus familiares. É a enfermeira, geralmente, o elo entre o paciente, a família, a equipe multiprofissional e a Unidade Básica de Saúde.

Assim sendo, o presente estudo de revisão crítica objetiva evidenciar o estado da arte da temática família da criança com doença falciforme e equipe de enfermagem, com vistas a contribuir para a discussão do tema, sistematizando informações relevantes.

\section{Metodologia}

Trata-se de uma revisão crítica da literatura especializada, cujos passos foram:

- Identificação do problema (elaboração da questão orientadora; estabelecimento das palavras-chaves e dos critérios de inclusão/exclusão de artigos)

- Seleção dos artigos

- Definição da informação a ser extraída dos artigos revisados, assim como sua análise, discussão e interpretação dos resultados e síntese do conhecimento.

Em vista dos temas: a) a doença falciforme é a doença hereditária monogênica mais comum na nossa população; b) é diagnosticada na triagem neonatal por meio do teste do pezinho e é impactante na vida familiar; c) é fundamentalmente necessário incluir as famílias no processo diagnóstico terapêutico; d) a enfermeira é profissional importante na orientação da família e foi elaborada a seguinte questão orientadora: "Qual é a produção científica relacionada à família da criança com doença falciforme e a equipe de enfermagem?"

Os critérios de inclusão utilizados foram: o tema dos artigos deve estar relacionado às famílias de crianças com doença falciforme; apresentar a equipe de enfermagem como participante do processo de cuidado; as publicações devem estar nas línguas inglesa, espanhola ou portuguesa; devem ter sido publicadas entre janeiro/2003 a agosto/2008; as publicações devem ter abstracts ou resumos disponíveis e indexados nas bases de dados Bireme (Biblioteca Virtual em Saúde do Centro Latino-Americano e do Caribe de Informação em Ciências da Saúde), Lilacs (Literatura Latino-americana e do Caribe em Saúde), BDENF (Base de Dados Bibliográficos Especializada na Área de Enfermagem do Brasil), SciELO Brasil (Scientific Electronic Library On Line), Medline (Base de dados da literatura internacional da área médica e biomédica, produzida pela NLM - National Library of Medicine, USA) e PubMed (Base de dados digital produzida pela National Library of Medicine, USA - no campo da Biociência).

Foram excluídos os artigos que não faziam menção à equipe de enfermagem e/ou à família, não tinham resumo ou abstract disponível ou em idioma diferente do português, espanhol ou inglês.

Utilizaram-se os seguintes descritores do DECs (Descritores em Ciências da Saúde - BVS/Bireme) e do MeSH (Medical Subject Headings): anemia falciforme (sickle cell anemia), doença da hemoglobina SC (hemoglobin SC disease), enfermagem (community health nursing), família (family practice), e criança (child).

Na base de dados PubMed estabeleceram-se os limites: artigos com texto completo gratuito, publicados nos últimos cinco anos, adicionados à PubMed nos últimos cinco anos, da área humana, nas línguas inglês e espanhol.

A fase de coleta de dados ocorreu no período de 31 de agosto a 30 de setembro/2008. Para selecionar as publicações, cada título e abstract foram lidos exaustivamente para confirmar se respondiam à questão orientadora e se preenchiam os critérios de inclusão e exclusão estabelecidos.

Em todas as bases de dados pesquisadas foram necessárias combinações mútuas de palavras.

\section{Resultados}

\section{Dimensão quantitativa}

$\mathrm{Na}$ PubMed, foram realizadas as seguintes combinações de descritores: (1) sickle cell anemia, nursing, family and child; (2) sickle cell anemia, nursing and family; (3) sickle cell anemia and nursing e (4) sickle cell anemia and family. De todas estas combinações, foram encontrados artigos somente com a última combinação (sete).

Dos sete artigos, três abordavam a enfermagem ou a família no resumo. Entretanto, apenas dois artigos faziam esta abordagem no texto completo. Estes resultados encontramse na Tabela 1.

Da pesquisa realizada na Bireme, com as combinações (1) anemia falciforme, enfermagem, família e criança e (2) anemia falciforme, enfermagem e família foram encontrados quatro artigos na base de dados Medline. Com a combinação (3) anemia falciforme e enfermagem, três artigos no Lilacs, 37 no 
Tabela 1. Distribuição de referências bibliográficas provenientes da PubMed de acordo com as palavras-chave

\begin{tabular}{|c|c|c|c|c|c|c|c|c|}
\hline $\begin{array}{c}\text { Base de } \\
\text { dados }\end{array}$ & $\begin{array}{l}\text { Palavras- } \\
\text {-chave }\end{array}$ & $\begin{array}{l}\text { Artigos } \\
\text { obtidos }\end{array}$ & $\begin{array}{c}\text { Sem } \\
\text { resumo }\end{array}$ & $\begin{array}{r}\text { Outro } \\
\text { idioma }\end{array}$ & Repetido & $\begin{array}{c}\text { Enfermagem/ } \\
\text { família no resumo }\end{array}$ & $\begin{array}{l}\text { Enfermagem/ } \\
\text { família no } \\
\text { artigo completo }\end{array}$ & Total \\
\hline \multirow{4}{*}{ PubMed } & $A F+E+F+C$ & 0 & 0 & 0 & 0 & 0 & 0 & 0 \\
\hline & $A F+E+F$ & 0 & 0 & 0 & 0 & 0 & 0 & 0 \\
\hline & $A F+E$ & 0 & 0 & 0 & 0 & 0 & 0 & 0 \\
\hline & $A F+F$ & 7 & 0 & 0 & 0 & 3 & 2 & 2 \\
\hline
\end{tabular}

AF: Anemia Falciforme; E: Enfermagem; F: Família; C: Criança

Tabela 2. Distribuição das referências bibliográficas provenientes da Bireme, de acordo com as palavras-chave

\begin{tabular}{|c|c|c|c|c|c|c|c|c|}
\hline $\begin{array}{l}\text { Base de } \\
\text { dados }\end{array}$ & $\begin{array}{l}\text { Palavras- } \\
\text {-chave }\end{array}$ & $\begin{array}{l}\text { Artigos } \\
\text { obtidos }\end{array}$ & $\begin{array}{c}\text { Sem } \\
\text { resumo }\end{array}$ & $\begin{array}{l}\text { Outro } \\
\text { idioma }\end{array}$ & Repetido & $\begin{array}{l}\text { Enf ou família } \\
\text { no resumo }\end{array}$ & $\begin{array}{c}\text { Enf ou família } \\
\text { no artigo completo }\end{array}$ & Total \\
\hline \multirow{4}{*}{ Lilacs } & $A F+E+F$ & 0 & 0 & 0 & 0 & 0 & 0 & 0 \\
\hline & $A F+E$ & 3 & 0 & 0 & 3 & 0 & 0 & 0 \\
\hline & $A F+F$ & 1 & 0 & 0 & 0 & 1 & 0 & 0 \\
\hline & $A F+E+F+C$ & 0 & 0 & 0 & 0 & 0 & 0 & 0 \\
\hline \multirow{4}{*}{ SciELO } & $A F+E+F$ & 0 & 0 & 0 & 0 & 0 & 0 & 0 \\
\hline & $A F+E$ & 4 & 0 & 0 & 0 & 3 & 3 & 3 \\
\hline & $\mathrm{AF}+\mathrm{F}$ & 1 & 0 & 0 & 1 & 0 & 0 & 0 \\
\hline & $A F+E+F+C$ & 0 & 0 & 0 & 0 & 0 & 0 & 0 \\
\hline \multirow{4}{*}{ BDENF } & $A F+E+F$ & 0 & 0 & 0 & 0 & 0 & 0 & 0 \\
\hline & $A F+E$ & 1 & 0 & 0 & 1 & 0 & 0 & 0 \\
\hline & $A F+F$ & 0 & 0 & 0 & 0 & 0 & 0 & 0 \\
\hline & $A F+E+F+C$ & 0 & 1 & 1 & 0 & 0 & 0 & 0 \\
\hline \multirow{4}{*}{ Medline } & $A F+E+F$ & 2 & 1 & 1 & 2 & 0 & 0 & 0 \\
\hline & $A F+E$ & 37 & 15 & 4 & 3 & 15 & 12 & 12 \\
\hline & $A F+F$ & 32 & 9 & 1 & 0 & 9 & 6 & 6 \\
\hline & $\mathrm{AF}+\mathrm{E}+\mathrm{F}+\mathrm{C}$ & 2 & 0 & 0 & 0 & 0 & 0 & 0 \\
\hline
\end{tabular}

AF: Anemia falciforme; E: Enfermagem; F: Família; C: Criança

Medline, quatro no SciELO e um na BDENF. Ainda com a combinação (4) anemia falciforme e família, um artigo no Lilacs, 32 no Medline e um no SciELO.

Dos 83 artigos excluíram-se os seguintes: dois que não foram passíveis de localização, apesar de todos os recursos de comutação bibliográfica, sete que estavam em francês, 26 que não possuíam abstracts ou resumo, dez que apareceram em mais de uma base de dados, restando 38 artigos. Destes, 28 apresentavam a enfermagem ou a família no resumo e 21 no artigo completo. Estes achados encontram-se na Tabela 2.

No final da trajetória descrita acima, foram selecionados 23 artigos, dos quais apenas 11 respondiam à questão orientadora e preenchiam os critérios estabelecidos, ou seja, a produção científica envolvendo a família da criança com doença falciforme e a equipe de enfermagem. Portanto, foram analisados 11 artigos.

\section{Dimensão qualitativa}

Para a análise crítica da produção sobre a família da criança com doença falciforme e a equipe de enfermagem, optou-se pela análise de conteúdo, ${ }^{8}$ que consiste em um conjunto de técnicas de análise de comunicação realizada com procedimentos sistematizados e objetivos de descrição do conteúdo das mensagens, de indicadores quantitativos, ou não, que possibilitem inferências acerca do que está em análise.

Assim, a análise da produção encontrada teve como foco os seguintes aspectos: informações sobre a totalidade do texto, classificação e enumeração segundo a presença ou ausência dos ítens: categoria profissional do autor, periódico, ano de publicação, país de origem, título, objetivo e metodologia (Tabela 3 ) e a relação entre a família da criança com doença falciforme e a equipe de enfermagem (Tabela 4).

Em seguida, foram identificadas as principais ideias contidas em cada artigo em torno de núcleos de significados, que chamamos de categorias. Comparados os diferentes núcleos de significados presentes nos artigos estudados, estes foram classificados em eixos mais abrangentes (temas) em torno dos quais giravam as discussões dos autores (Tabela 5).

Após a análise dos conteúdos dos artigos, buscou-se estabelecer um diálogo entre os temas encontrados e a ques- 
Tabela 3. Organização dos artigos segundo o título, a categoria profissional dos autores, o ano de publicação, o periódico, o país de origem; a metodologia e os objetivos

\begin{tabular}{|c|c|c|c|c|c|c|}
\hline Título do artigo & Autor & Ano & Periódico & Origem & Método & Objetivo \\
\hline $\begin{array}{l}\text { 1. Quality of life of female care } \\
\text { givers of children with sickle cell } \\
\text { disease: a survey }\end{array}$ & $2,3,4$ & 2008 & Haematologica & Amsterdam & TAAQoL & $\begin{array}{l}\text { Investigar a qualidade de vida (QV) } \\
\text { de cuidadores de crianças com DF }\end{array}$ \\
\hline $\begin{array}{l}\text { 2. Assistência de enfermagem } \\
\text { na doença falciforme nos } \\
\text { serviços de atenção básica }\end{array}$ & 1 & 2007 & $\begin{array}{c}\text { Rev Bras } \\
\text { Hematol Hemoter. }\end{array}$ & Brasil & Descritivo & $\begin{array}{l}\text { Enfocar a enfermidade em seus } \\
\text { aspectos culturais, sociais e de } \\
\text { atenção à saúde }\end{array}$ \\
\hline $\begin{array}{l}\text { 3. Therapy preference and } \\
\text { patients with severe sickle cell } \\
\text { anemia and their decision- } \\
\text { making among families }\end{array}$ & 1,4 & 2007 & $\begin{array}{l}\text { Pediatr Blood } \\
\text { Cancer }\end{array}$ & USA & $\begin{array}{l}\text { Estudo } \\
\text { prospectivo }\end{array}$ & $\begin{array}{l}\text { Investigar o processo de tomada de } \\
\text { decisão entre os pacientes com DF } \\
\text { e suas famílias quanto à escolha ou } \\
\text { desistência do tratamento. }\end{array}$ \\
\hline $\begin{array}{l}\text { 4. Structured telephone-based } \\
\text { outreach using nonmedical } \\
\text { personnel can improve } \\
\text { adherence to comprehensive } \\
\text { care in families of children } \\
\text { with sickle cell disease }\end{array}$ & 4 & 2006 & Am J Hemato & USA & $\begin{array}{l}\text { Cross- } \\
\text { sectional } \\
\text { survey }\end{array}$ & $\begin{array}{l}\text { Investigar a viabilidade e } \\
\text { aceitabilidade de seguimento e } \\
\text { educação, por meio de telefone, } \\
\text { para famílias com uma criança } \\
\text { com DF e seu impacto na adesão } \\
\text { ao tratamento }\end{array}$ \\
\hline $\begin{array}{l}\text { 5. Adjustment difficulties } \\
\text { of adolescents with } \\
\text { sickle cell disease }\end{array}$ & 1 & 2004 & $\begin{array}{l}\text { J Child Adolesc } \\
\text { Psychiatr Nurs }\end{array}$ & USA & $\begin{array}{l}\text { Revisão da } \\
\text { literatura }\end{array}$ & $\begin{array}{l}\text { Explorar como os fatores } \\
\text { psicossociais específicos podem } \\
\text { colaborar no ajuste futuro desta } \\
\text { população }\end{array}$ \\
\hline $\begin{array}{l}\text { 6. Antenatal screening } \\
\text { for haemoglobinopathies } \\
\text { in primary care }\end{array}$ & 1,4 & 2005 & Br J Gen Pract & UK & $\begin{array}{l}\text { Sistema } \\
\text { participatório } \\
\text { integral }\end{array}$ & $\begin{array}{l}\text { Avaliar se a triagem geral reduz a } \\
\text { idade gestacional de triagem } \\
\text { antenatal e identificar implicações } \\
\text { desta nova forma de triagem para } \\
\text { profissões diferentes }\end{array}$ \\
\hline $\begin{array}{l}\text { 7. Enhancing self-management } \\
\text { in children with sickle cell } \\
\text { disease through playing a } \\
\text { CD-ROM educational game: } \\
\text { a pilot study }\end{array}$ & 1 & 2007 & Pediatric Nurs & USA & $\begin{array}{l}\text { Theoretical } \\
\text { frame work } \\
\text { by Lieberman } \\
\text { (2001) }\end{array}$ & $\begin{array}{l}\text { Determinar: o conhecimento da } \\
\text { criança sobre DF e o manejo dos } \\
\text { sintomas, a confiança da criança } \\
\text { no manejo dos seus sintomas e } \\
\text { investigar a eficácia de uma } \\
\text { intervenção educacional simples para } \\
\text { aumentar tanto o conhecimento como } \\
\text { a confiança dessas crianças }\end{array}$ \\
\hline $\begin{array}{l}\text { 8. Written educational materials } \\
\text { for families of chronically ill } \\
\text { children }\end{array}$ & 1 & 2007 & $\begin{array}{l}J \text { Am Acad } \\
\text { Nurse Pract }\end{array}$ & USA & $\begin{array}{l}\text { Avaliação } \\
\text { sistemática }\end{array}$ & $\begin{array}{l}\text { Fornecer informação na avaliação } \\
\text { dos materiais educacionais escritos } \\
\text { e ilustrar a avaliação do Sickle Cell } \\
\text { Disease: A Family Guide usado para } \\
\text { crianças com DF e suas famílias }\end{array}$ \\
\hline $\begin{array}{l}\text { 9. Sickle cell disease: health } \\
\text { promotion and maintenance and } \\
\text { the role of primary care nurse } \\
\text { practitioners }\end{array}$ & 1 & 2003 & $\begin{array}{l}J \text { Am Acad } \\
\text { Nurse Pract }\end{array}$ & USA & $\begin{array}{l}\text { Revisão } \\
\text { literatura }\end{array}$ & $\begin{array}{l}\text { Discutir o papel da enfermeira com } \\
\text { relação à identificação precoce de } \\
\text { indivíduos afetados; monitorização } \\
\text { efetiva e triagem; manejo e profilaxia } \\
\text { efetivos da dor e educação para a } \\
\text { saúde de pacientes com DF }\end{array}$ \\
\hline $\begin{array}{l}\text { 10. Sickle cell anaemia } 2 \text { : } \\
\text { Management approaches } \\
\text { of painful episodes }\end{array}$ & 1 & 2005 & Br J Nurs & UK & $\begin{array}{l}\text { Revisão do } \\
\text { guideline } \\
\text { nacional }\end{array}$ & $\begin{array}{l}\text { Mostrar que escolher o analgésico } \\
\text { certo nem sempre é fácil }\end{array}$ \\
\hline $\begin{array}{l}\text { 11. Care of patients with } \\
\text { haemoglobin abnormalities: } \\
\text { nursing management }\end{array}$ & 1,4 & 2006 & Br J Nurs & UK & descritivo & $\begin{array}{l}\text { Fornecer parecer sobre o } \\
\text { cuidado de enfermagem para } \\
\text { pacientes com DF }\end{array}$ \\
\hline
\end{tabular}

1: Enfermeiros; 2: Psicólogos; 3: Biomédicos; 4: Médicos; DF: doença falciforme 
Tabela 4. Organização dos artigos segundo sua relação com a enfermagem e a família da criança com doença falciforme

\begin{tabular}{lll}
\hline Artigo & \multicolumn{1}{c}{ Relação com a enfermagem } & \multicolumn{1}{c}{ Relação com a família } \\
\hline $\begin{array}{l}\text { 1. Quality of life of female care } \\
\text { givers of children with sickle cell } \\
\text { disease: a survey }\end{array}$ & $\begin{array}{l}\text { Os médicos e outros profissionais de saúde precisam } \\
\text { estar cientes das necessidades desses cuidadores }\end{array}$ & $\begin{array}{l}\text { Relata como cuidar de uma criança com DF } \\
\text { interfere com as atividades da família, } \\
\text { gerando estresse psicológico }\end{array}$
\end{tabular}

2. Assistência de enfermagem na doença falciforme nos serviços de atenção básica

3. Therapy preference and patients with severe sickle cell anemia and their decision-making among families

4. Structured telephone-based outreach using nonmedical personnel can improve adherence to comprehensive care in families of children with sickle cell disease

5. Adjustment difficulties of adolescents with sickle cell disease.

6. Antenatal screening for haemoglobinopathies in primary care

7. Enhancing self-management in children with sickle cell disease through playing a CD-ROM educational game: a pilot study

8. Written educational materials for families of chronically ill children

9. Sickle cell disease: health promotion and maintenance and the role of primary care nurse practitioners

10. Sickle cell anaemia 2 : Management approaches of painful episodes

11. Care of patients with haemoglobin abnormalities: nursing management.
A assistência de enfermagem na atenção primária à saúde como agente político de transformação social exercendopapel relevante na longevidade e QV das pessoas com DF. Descreve os cuidados de enfermagem nas intercorrênciamais comuns

A enfermeira educadora orienta quanto às diferentes modalidades de tratamento explicando-as até a compreensão completa

O enfermeiro é o contato do paciente no utreach calling program; o trabalho multiprofissional no cuidado abrangente, reduzindo a morbi- mortalidade destes pacientes

Os enfermeiros têm oportunidade de causar impacto significativo na vida dos adolescentes com DF se intervêm de forma a promover ajuste biológico e psicossocial

O enfermeiro atuando no aconselhamento genético e na triagem antenatal de famílias de pessoas com DF

O enfermeiro participou na elaboração do material educativo e na aplicação do teste

Um dos principais objetivos do enfermeiro é educar pacientes e cuidadores sobre a doença e seu manejo

A importância da enfermeira conhecer toda as complicações relacionadas à DF; atuação da enfermeira na educação das famílias, reduzindo as taxas de morbidade e mortalidade associadas a esta doença

As enfermeiras podem fornecer a base para o desenvolvimento de programas bem sucedidos de manejo da dor, construindo pontes entre a teoria e a prática

Enfermeira como educadora na prevenção de crises: importância da enfermeira ter conhecimento das opções de tratamento e das complicações da doença
A família deve receber visita e orientação familiar por parte da equipe de enfermagem na atenção primária

A familia participando da escolha do melhor tratamento para seu filho

A problemática da adesão da família ao tratamento e a necessidade de receber cuidado integral

O ajuste familiar é um preditor importante de como um adolescente com DF se ajustará à doença; como a família enfrenta o fato de ter um membro com DF e com a severidade das crises de dor

Acompanhamento do pré-natal de grupos étnicos de risco para DF

Avalia como a família é afetada pelas crises de dor da criança e o que afamília tem de conhecimento sobre a doença

Como a família compreende a informação recebida através do material educacional escrito

Impacto na família dos problemas psicossociais relacionados à doença

Incluir o paciente e a família no processo terapêutico

Como a orientação prática pode ajudar a família a enfrentar os efeitos da DF tão orientadora, realizando-se a redação das sínteses interpretativas de cada tema.

\section{Análise crítica da produção - família da criança com doença falciforme e equipe de enfermagem}

Dos 11 artigos encontrados, nove tinham enfermeiros como autores, quatro médicos, um psicólogo e um biomédico.
Quanto ao ano de publicação, 2007 teve o maior número de publicações (4). Quanto ao país de origem, somente um artigo tinha origem brasileira, sendo a maioria norte-americana. Seis artigos foram publicados em periódicos de enfermagem, três em periódicos de hematologia, um em periódico de oncologia e um em periódico não relacionado à saúde. Quanto à metodologia, a metade dos trabalhos publicados em periódicos de enfermagem é de revisão de literatura (3). 
Tabela 5. Núcleos de sentido: Categorias e Temas

\begin{tabular}{|c|c|}
\hline Categorias & Temas \\
\hline $\begin{array}{l}\text { 1. Necessidade do enfermeiro ter } \\
\text { conhecimento sobre as necessidades dos } \\
\text { cuidadores. } \\
\text { 2. Importância do enfermeiro conhecer as } \\
\text { opções terapêuticas e as complicações } \\
\text { da doença } \\
\text { 3. Enfermeiro como agente de transformação } \\
\text { social } \\
\text { 4. O enfermeiro na atenção primária }\end{array}$ & $\begin{array}{l}\text { 1. Conhecimento } \\
\text { científico }\end{array}$ \\
\hline $\begin{array}{l}\text { 5. Enfermeiro como agente de ajuste familiar } \\
\text { 6. Enfermeiros sendo a base para o } \\
\text { desenvolvimento de programas no manejo } \\
\text { da dor } \\
\text { 7. Enfermeiros sendo o elo entre a teoria e a } \\
\text { prática }\end{array}$ & $\begin{array}{l}\text { 2. Assistência } \\
\text { de enfermagem }\end{array}$ \\
\hline $\begin{array}{l}\text { 8. Enfermeiros reduzindo a morbi-mortalidade. } \\
\text { 9. Enfermeiro aumentando a adesão ao } \\
\text { tratamento } \\
\text { 10. Enfermeiro no aconselhamento genético } \\
\text { 11. Enfermeiro na prevenção de crises } \\
\text { 12. Enfermeiro na orientação quanto à doença } \\
\text { e manejo da dor } \\
\text { 13. Enfermeiro na elaboração de material } \\
\text { educativo } \\
\text { 14. A família participando da escolha } \\
\text { terapêutica } \\
\text { 15. O enfermeiro ajudando a família a manejar } \\
\text { os efeitos da doença } \\
\text { 16. Aumentar a confiança da criança no } \\
\text { automanejo da doença }\end{array}$ & 3. Educação \\
\hline
\end{tabular}

A partir das ideias centrais dos artigos e do agrupamento dessas ideias em torno de núcleos de significados, chegou-se a 16 categorias que compõem três grandes temas: conhecimento científico, assistência de enfermagem e educação.

Tais temas, embora possam ser entendidos como classificações que estruturam a discussão, necessariamente não seguem o princípio de exclusão mútua. Eles são apenas prismas da discussão dos significados atribuídos às idéias que, em determinados momentos, podem sobrepor-se.

\section{Conhecimento cientifico}

Em primeiro lugar, verificou-se que a triagem neonatal ou antenatal é uma preocupação em vários países, ${ }^{9-10} \mathrm{e}$ é nesse momento que se inicia a participação do enfermeiro na assistência à família. De acordo com a literatura pesquisada, especificamente no que tange à temática conhecimento científico, o enfermeiro deve conhecer a doença falciforme e suas consequências físicas, sociais e psicológicas para a criança e sua família, o impacto causado na vida familiar, assim como seu papel como transformador político e social, atuando junto às associações de pacientes e a políticas públicas de saúde. ${ }^{11-16}$

Nos programas do Ministério da Saúde relacionados às hemoglobinopatias, muito se tem falado em orientação genética, ${ }^{3}$ mas como e quando o profissional enfermeiro está sendo preparado? Está adquirindo conhecimento técnico, científico, ético, para atuar em área tão nova para a enfermagem brasileira?

O único artigo brasileiro encontrado foi escrito por uma enfermeira, fundadora e presidente da Associação de Anemia Falciforme do Estado de São Paulo - Aafesp, e aponta a preocupação em disseminar conhecimento quanto ao atendimento às intercorrências na doença falciforme junto aos profissionais da atenção primária, ${ }^{15} \mathrm{e}$ não somente nos centros especializados, como acontece hoje. Esta observação é relevante, visto que em nosso país estes pacientes muitas vezes encontram-se distantes dos centros e poderiam ser mais adequadamente atendidos se houvesse profissionais capacitados para tal nas unidades básicas de saúde.

Adquirir conhecimento sobre a doença falciforme não é tarefa difícil atualmente com a grande quantidade de artigos científicos disponíveis. Mas, talvez, para o cuidar em enfermagem, não seja suficiente. Os profissionais hoje têm percebido que não basta conhecer "a doença", é necessário conhecer "a pessoa doente".

"Foi só muito mais tarde, anos depois de formado, que aprendi que cada pessoa tinha uma história. Uma história absolutamente impar e original, uma história intransferivel... O que difere uma história da outra e a individualiza é exatamente o conteúdo emocional embutido nelas... Para a maioria dos profissionais de saúde, em geral esse tipo de saber não foi suficientemente ensinado e aprendido, o que dificulta muito a relação profissional-paciente e gera conflitos desnecessários"(Hoher e Wagner, 2006, p.23)

\section{Assistência de enfermagem}

No tema assistência de enfermagem, é interessante observar que, a partir do conhecimento científico, para uma assistência de enfermagem adequada, o enfermeiro deve fazer a ligação entre a teoria e a prática, ${ }^{17}$ exercitar sua capacidade de ser um agente facilitador do ajuste familiar ${ }^{16}$ e elaborar protocolos de manejo da dor ${ }^{9,17}$ e outras intercorrências comuns à doença falciforme. ${ }^{15}$

A assistência de enfermagem inicia-se no primeiro contato com os pais, no momento da orientação genética, quando os pais se deparam com o fato de que o filho sonhado não existe mais e forte sentimento de culpa se instala no casal.

Nesse momento, a família procura, por intermédio dos profissionais de saúde, uma explicação para as causas do problema, bem como sua nomeação. Além disso, há a busca por aspectos positivos em relação ao desenvolvimento do filho, que amenizem o sofrimento e facilitem o processo de aceitação. No entanto, muitas vezes o momento do diagnóstico deixa os pais confusos e sem orientação adequada, interferindo desse modo na vinculação com a criança e, sobretudo, no que diz respeito às falsas expectativas, influenciando o processo de aceitação ou rejeição do filho real. ${ }^{18}$ 
O que se observa é que a maioria dos profissionais não se encontra preparada para realizar esse trabalho da forma recomendada. Falta capacitação para enfrentar a situação, o que é coerente com uma sociedade mecanicista, que privilegia a eficiência e o aproveitamento de tempo.

Mas o enfermeiro é um dos profissionais da área da saúde cuja essência e especificidade é o cuidado ao ser humano, individualmente, na família ou na comunidade, desenvolvendo atividades de promoção, prevenção de doenças, recuperação e reabilitação da saúde, ou atuando em equipes.

A enfermagem se responsabiliza, por meio do cuidado, pelo conforto, acolhimento e bem-estar dos pacientes, seja prestando o cuidado, seja coordenando outros setores para a prestação da assistência ou promovendo a autonomia dos pacientes pela educação em saúde. ${ }^{19}$ Quando se trata de cuidar de pessoas com doença crônica, isto é particularmente verdadeiro. É fundamental, para o paciente e sua família, que se crie um vínculo entre eles e o enfermeiro.

Daí a importância do enfermeiro, a partir do momento da orientação genética, quando se inicia o vínculo com esta família, procurar compreender o significado da criança na família, neste contexto, em particular, pois, de fato, na prática, o cuidado se apresenta de forma histórica e contextual. Devido à essência da enfermagem ser o cuidado, não pode prescindir de seus aspectos afetivos, da sensibilidade e da intersubjetividade que se realiza na prática cotidiana.

\section{Educação}

No artigo "Refletindo sobre o cuidar e o ensinar na enfermagem", os autores constataram que cuidar e ensinar são atividades essenciais no cotidiano da enfermagem e, por isso mesmo, precisam estar cada vez mais inter-relacionadas. Cuidar é vivenciar um encontro. ${ }^{20}$

Apesar da existência de trabalhos quanto ao papel do enfermeiro como educador, é notório, no tema educação, a abrangência do papel do enfermeiro como educador na doença falciforme. Desde o aconselhamento genético, ${ }^{10} \mathrm{o}$ manejo da dor, ${ }^{13,17}$ a prevenção das crises $^{13}$ até a adesão ao tratamento, ${ }^{18}$ a participação do enfermeiro deve ser efetiva na orientação dessas famílias. Em geral, os estudos revisados constataram influências dessas questões tanto na promoção da saúde quanto na intervenção da doença. ${ }^{9,21}$

O ensinar, nesses momentos, mostra que cuidar significa presença junto à criança/família. Ao vivenciar a relação com a família de uma criança com doença falciforme, o enfermeiro estuda e desenvolve sua prática de aprendizado e de ensino sobre o cuidado humano, criando o fazer profissional e, nesse processo de aprender/ensinar/criar, ele concebe, organiza e expressa ações de cuidado. Na doença falciforme, o enfermeiro cuida e ensina a cuidar. Ensinar transforma-se em aprender, no esforço de entender o outro.

E, mais importante, estas ações de ensinar/compreender/cuidar são fundamentais para que o paciente tenha acesso ao melhor tratamento disponível e melhor sobrevida e qualidade de vida. ${ }^{15,19}$

\section{Considerações finais}

Respondendo à questão orientadora "qual é a produção científica relacionando a família da criança com doença falciforme e a equipe de enfermagem?", no intervalo de cinco anos foram encontrados 11 artigos, sendo apenas um de origem nacional, no qual categorias e temas selecionados reforçam que o enfermeiro é um importante agente na orientação dos pais e pacientes com doença falciforme, ${ }^{14}$ como também elo entre estes e a equipe multiprofissional ${ }^{17-}$ 19 e tem papel fundamental na assistência aos pacientes. ${ }^{8,13,15,16,20}$

As fontes revisadas apontam ainda para duas questões importantes: (a) na prática, a família deve ser inserida no processo do cuidado como agente ativo, participante no processo decisório do tratamento do filho; ${ }^{12}$ e (b) a assistência de enfermagem deve ser baseada, além do conhecimento teórico, nas necessidades dos pacientes e de suas famílias. ${ }^{8,11,13,14}$ No entanto, estudos sob a dimensão sociocultural ainda se fazem necessários.

Como a maioria dos artigos era de origem americana ou britânica, tanto as populações de pacientes como o sistema de saúde são diferentes do brasileiro. Portanto, há necessidade de se realizarem trabalhos nacionais onde os cuidadores e pacientes possam ser ouvidos para o planejamento da assistência de enfermagem de acordo com a nossa realidade.

Apesar da doença falciforme ser de grande prevalência em nosso país, ${ }^{2}$ e o impacto da orientação genética e cuidado abrangente serem comprovadamente um marco na história da sobrevida dessas pessoas, ${ }^{3-4}$ configurando uma mudança paradigmática no cuidado à criança e à família, na enfermagem brasileira não há total correspondência com a produção teórica, levando ao desenvolvimento de uma prática assistencial muitas vezes sem a devida sustentação teórica.

Portanto, pode-se afirmar que existe uma lacuna sobre esta temática na área de enfermagem, e pesquisas são necessárias para aprofundamento nas relações entre assistência de enfermagem, educação, famílias, doença falciforme e saúde.

Vale ressaltar que a produção internacional encontrada, em sua maioria concentra-se em revisões da literatura, com escassez de pesquisas que avaliem o processo de trabalho do enfermeiro nesta área. Esta lacuna de conhecimento dificulta adequada avaliação deste processo, tanto para a criança e sua família quanto para a equipe prestadora da assistência e as políticas públicas de saúde.

Nesse sentido, as investigações com abordagem qualitativa podem contribuir para que tais relações tornem-se mais visíveis a partir dos cenários de promoção da saúde. 


\section{Abstract}

This critical literature review aims at demonstrating the state of the art of a thematic family with a sickle cell disease child and the nursing team. The PubMed, Lilacs, SciELO, and BDENF databases were searched using the key words: sickle cell anaemia, nursing, family and child. Eleven articles were selected and the important points in respect to the quanti-qualitative aspects of the studies are described. A referential analysis of the content was performed which identified the following themes: scientific knowledge, nursing care and education. The necessity of specific knowledge about sickle cell disease was demonstrated: this is important for nursing care to be effective and contribute to a better quality of life and so that the survival of these children is prolonged. It is worth noting that the Brazilian production on sickle cell disease, in general, is scarce and incipient in particular in respect to studies about the family with a sickle cell disease child and nursing team. Rev. Bras. Hematol. Hemoter. 2010;32(3):257-264.

Key words: Anemia, sickle cell; child; family; nursing care.

\section{Referências Bibliográficas}

1. Lobo CLC, Marra VN, Silva RMG. Crises dolorosas na doença falciforme. Rev Bras Hematol Hemoter. 2007;29(3):247-58.

2. Ramalho AS, Magna LA, Paiva e Silva RSA. Portaria n. ${ }^{\circ} 822 /$ 01 do Ministério da Saúde e as peculiaridades das hemoglobinopatias em saúde pública no Brasil. Cad Saúde Pública. 2003;19 (4):1195-99.

3. U.S. Department of Health and Human Services. The Management of Sickle Cell Disease, Division of Blood Diseases and Resources; 2004. 188 p.

4. Pean A, Farrel MH. Initially misleading communication of carrier results after newborn genetic screening. Pediatrics. 2005;116(6): 1499-1505.

5. Taylor S, Moore KJ. Emergency nursing care of pediatric sickle cell patients: meeting the challenge. Pediatr Emerg Care. 2001; 17(3):220-25.

6. Brasil. Ministério da Saúde. Programa Nacional de Atenção Integral às Pessoas com Doença Falciforme e outras Hemoglobinopatias. Aconselhamento, orientação e informação genética em doença falciforme. Brasília; 2005.

7. Pedro ICS, Galvão CM, Rocha SMM, Nascimento LC. Apoio social e famílias de crianças com câncer: revisão integrativa. Rev Latino-Am Enfermagem. 2008;16(3):477-83.

8. Bardin L. Análise de Conteúdo. Lisboa (POR): Edições 70; 1977

9. Tanyl RA. Sickle cell disease: health promotion and maintenance and the role of primary care nurse practitioners. J Am Acad Nurse Pract. 2003;15(9):389-97.

10. Thomas P, Oni L, Alli M, Hilaire JS, Smith A, Leavey C, Banarsee R. Antenatal screening for haemoglobinopathies in primary care: a whole system participatory action research project. Br J Gen Pract. 2005;55(515):424-8.

11. Tweel XW, Hatzmann J, Ensink E, Lee JH, Peters M, Fijnvandraat $\mathrm{K}$, et al. Quality of life of female caregivers of children with sickle cell disease a survey. Haematologica. 2008;93(4):588-93.

12. Hankins J, Hinds P, Day S, Carroll Y, Li CS, Garvie P, et al. Therapy preference and decision-making among patients with severe sickle cell anemia and their families. Pediatr Blood Cancer. 2007;48(7):705-10.
13. Khattab AD, Rawlings B, Ali IS. Care of patients with haemoglobin abnormalities: nursing management. Br J Nurs. 2005;15(19): 1057-62.

14. Mahat G, Scoloveno MA, Donnelly CB. Written educational materials for families of chronically ill children. J Am Acad Nurse Pract. 2007;19(9):471-76.

15. Kikuchi BA. Assistência de enfermagem na doença falciforme nos serviços de atenção básica. Rev Bras Hematol Hemoter. 2007; 29(3):331-38.

16. Pinckney RB, Stuart GW. Adjustment difficulties of adolescents with sickle cell disease. J Child Adolesc Psychiatr Nurs. 2004; 17(1):5-12.

17. De D. Sickle cell anaemia 2: management approaches of painful episodes. Br J Nurs. 2005;4(9):484-89.

18. Hoher SP, Wagner ADL. A transmissão do diagnóstico e de orientações a pais de crianças com necessidades especiais: a questão da formação profissional. Estudos de Psicologia Campinas. 2006; 23(2):113-25

19. Rocha SMM, Almeida MCP. O processo de trabalho da enfermagem em saúde coletiva e a interdisciplinaridade. Rev Latino-Am Enfermagem. 2000;8(6):96-101.

20. Camacho ACLF, Santo FH. Refletindo sobre o cuidar e ensinar em enfermagem. Rev Latino-Am Enfermagem. 2001;9(1):13-7.

21. Patik M, Phillips L, Kladny B, Captain A, Gettig E, Krishnamurti L. Structured telephone-based outreach using nonmedical personnel can improve adherence to comprehensive care in families of children with sickle cell disease. Am J Hematol. 2006;81(6):462-64.

22. Yoon SL, Godwin A. Enhancing self-management in children with sickle cell disease through playing a CD-Rom educational game: a pilot study. Pediatric Nurs. 2007;3(1):60-72.

Avaliação: Editor e dois revisores externos

Conflito de interesse: sem conflito de interesse

Recebido: 29/06/2009

Aceito: 15/07/2009 